\title{
Effect of maternal and child factors on stunting: partial least squares structural equation modeling
}

\author{
Agus Santosa, S.Kep., Ns., M.Kep, Essa Novanda Arif, S.Kep, Dinal Abdul Ghoni, S.Kep \\ Universitas Muhammadiyah Purwokerto, Purwokerto, Indonesia
}

\begin{abstract}
Background: Stunting is affected by various factors from mother and child. Previous studies assessed only one or more influencing variables. Unfortunately, nor the significant influence of maternal and child factors nor the indicators contributing to maternal and child factors that affect the stunting incidence have ever been analyzed.
\end{abstract}

Purpose: This study analyzed the effect of maternal and child factors on stunting and the significant indicators that shape the maternal and child factors that impact stunting.

Methods: This was a case-control study. Overall, 132 stunted children and 132 nonstunted children in Purbalingga Regency, Central Java Province, participated in the research. Direct interviews and medical record reviews were conducted to assess the studied variables. The research data were tested using the partial least squares structural equation with a formative model.

Results: Maternal factors directly affected the occurrence of stunting ( $t=3.527, P<0.001)$ with an effect of $30.3 \%$. Maternal factors also contributed a significant indirect effect on stunting through child factors $(t=4.762, P<0.001)$ with an effect of $28.2 \%$. Child factors affected the occurrence of stunting ( $t=$ $5.749, P<0.001)$ with an effect of $49.8 \%$. The child factor was influenced by maternal factor with an effect of $56.7 \%(t=10.014$, $P<0.001)$. The moderation analysis results demonstrated that maternal and child factors were moderate predictive variables of stunting occurrence.

Conclusion: Child factors have more significant and direct effects on stunting than maternal factors but are greatly affected by them.

Key words: Child, Mothers, Stunting, Growth disorders

\section{Key message}

Question: What effects do maternal and child factors have on stunting? Are there significant indicators of stunting?

Finding: Child and maternal factors had $49.8 \%$ and $30.3 \%$ effects on stunting, respectively. The primary child factor was infant formula dose, while the primary maternal factor was nutritional status.
Meaning: More attention to nutritional status during pregnancy and ensuring the appropriate dose of infant formula at ages 6-24 months can prevent stunting.

\section{Introduction}

A problem of growth disorder among children (stunting) is a malnutritional problem in the world, especially in the poor and developing countries. A child is said to have a stunted growth if his body growth compared to his age is under 2 standard deviation (-2SD), under the median of World Health Organization Growth Charts. Stunting is frequently associated with a chronic malnutrition, making them too short in his age. The impact of stunting is not only bad for children, but for the future of a country. High rate of stunting can be a burden for a country in the future. It can be assumed that stunting is an indicator of a country's advancement. Children who suffered from stunting may experience pathological changes, such as decline of physics, cognitive performance, neurodevelopmental, and increase metabolic disease risk up to their adulthood. Unquestionably, those changes can burden the family's economy and the potential loss of skilled human resources for the country. Several experts view this condition as 'stunting syndrome. ${ }^{1-3)}$

Stunting is affected by various factors, both from the maternal and from the child. Many studies have proved the factors which contribute a significant role in stunting, including parental education, ${ }^{4)}$ maternal age at pregnancy, ${ }^{5)}$ socioeconomic condition, ${ }^{6}$ nutritional status of the pregnant mother, $\left.{ }^{7}\right)$ infectious diseases during pregnancy ${ }^{8)}$ and other factors at prenatal. Birth weight, ${ }^{9)}$ prematurity, ${ }^{10)}$ exclusive breastfeeding, ${ }^{11)}$ infectious diseases during infancy, ${ }^{12)}$ and other factors at birth were also correlated with the stunting.

However, previous studies only assessed few variables. The significant of the maternal and child factors, and the indicators contributing significantly to maternal and child factors have never been analyzed. In order to fill the existing gap, this study was aimed to analyze the immense effect of maternal and child

\footnotetext{
Corresponding author: Agus Santosa, S.Kep., Ns., M.Kep, Universitas Muhammadiyah Purwokerto, Jl. KH. Ahmad Dahlan, PO BOX 202 Purwokerto 53182 Kembaran Banyumas, Purwokerto, Indonesia 


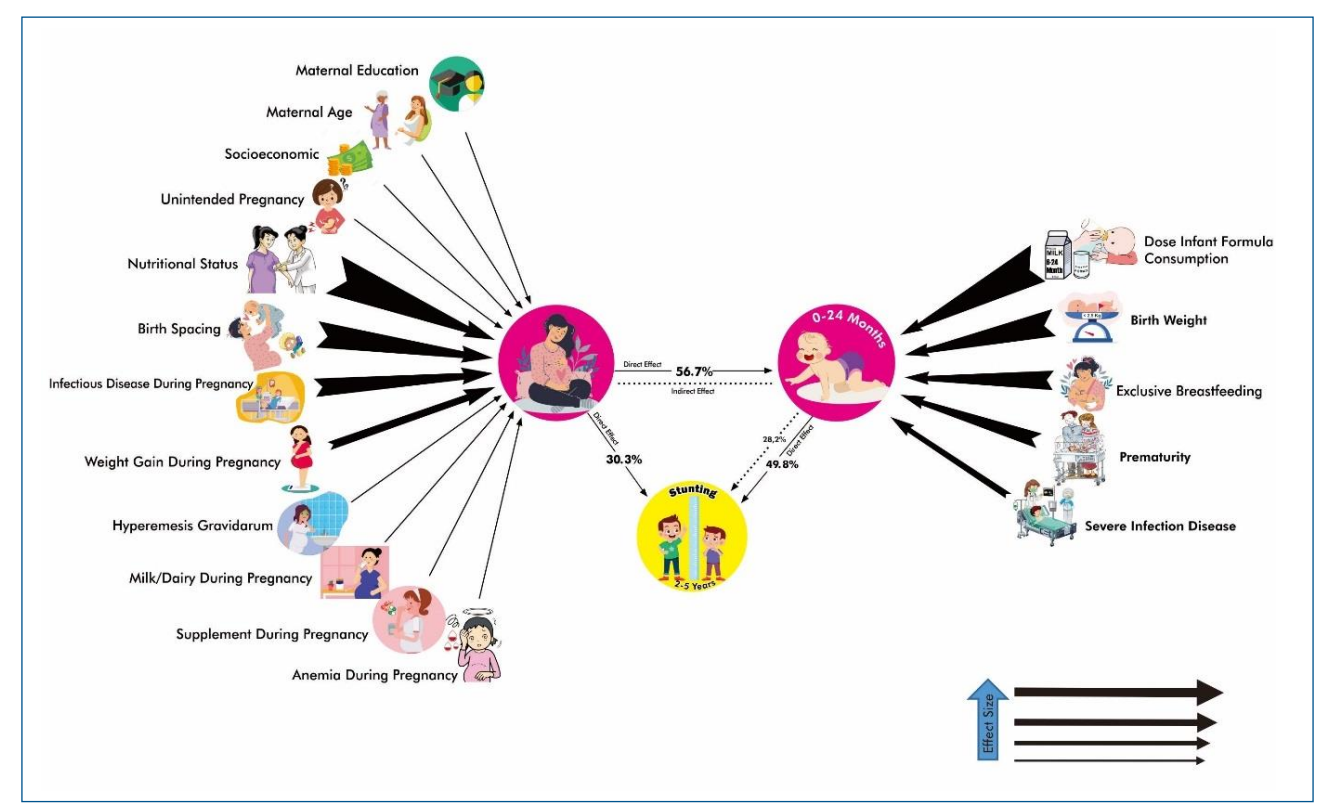

Graphic abstract

factors have on the incidence of stunting and the variables/indicators contribute significantly to maternal and child factors that impact the occurrence of stunting.

\section{Methods}

\section{Study design}

This is a case-control study design.

\section{Study location and respondents}

The research was conducted in Purbalingga Regency from September 2019 to March 2020. The regency was selected since it has the highest number of stunting cases in Central Java, Indonesia. A total of 132 stunted child and 132 nonstunted child participated in this study. ${ }^{13)}$

The study samples were obtained randomly with the inclusion criteria of case group are male or female child, 2-5 years old, and their height-for-age $z$-score (HAZ) below -2SD. The exclusion criteria are the child with dwarfisme, down syndrome, and others with any data varible lost in the investigation process, incomplete medical record, and inaccurate information from the interview; these subjects will not taken into account in the analysis.

The inclusion criteria of control group are male and female child, 2-5 years old, and HAZ 0 (median) or $>2 S D$. The exclusion criteria for control group include the individual with a data lost in one of the variabels, incomplete medical record, and the one with invalid data in the interview.

\section{Variables and measurements}

This study has 3 types of variables: manifest variables or indicators, latent variables, and moderating variables. Indicator variables which inform or construct latent variables for maternal factors are maternal education (whether or not they graduated from junior high school), maternal age $(20-35$ years or $<20$ years and $>35$ years), socioeconomic status (household income below or above the national standard), unintended pregnancy (intended or uninteded pregnancy, including extramarital), birth spacing (Interval between the deliveries $<2$ years or $>2$ years), milk/dairy consumption during pregnancy (whether or not the mother consumed milk during the pregnancy), supplement during pregnancy (whether or not the mother consumed the tablets of Fe, Vitamin, and folate acid), anemia during pregnancy (whether or not mother experienced anemia during pregnancy), nutritional status (the midupper arm circumference during pregnancy $\geq 23.5 \mathrm{~cm}$ or $<23.5 \mathrm{~cm}$ ), weight gain during pregnancy (the weight gain during pregnancy $>7 \mathrm{~kg}$ or $<7 \mathrm{~kg}$ ), infectious disease during pregnancy (wether or not the mother suffered a severe infectious disease during pregnancy), and hyperemesis gravidarum (whether or not mother had a hyperemesis gravidarum).

The indicator variables that construct the latent variable of child factors are birth weight (birth weight $<2.5 \mathrm{~kg}$ or $\geq 2.5 \mathrm{~kg}$ ), duration of pregnancy/prematurity (whether the birth is aterm or preterm/premature), exclusive breastfeeding (whether or not the baby was exclusively breastfed for 6 months), a dose of infant formula consumption (whether or not the baby was given a formula feeding after 6 months to 2 years old according to the recommended dosage), and severe infectious disease (wheter or not the baby had a severe infections between 0-24 months).

The indicator variable that informs or constructs the latent variable of stunting is the occurrence of stunting. The moderation variable is a combination of the mother's latent factor variable and the child's. The indicator variables were obtained directly from respondents by conducting interviews and checking maternal and child health medical records (or Kartu Kesehatan Ibu dan 
Anak, in Indonesian). In contrast, latent variables were obtained from statistical analysis of the indicator variables that construct the latent variables. The variable of data indicator in this study is nominal data.

\section{Statistical analysis}

The research data were tested using partial least squares structural equation modeling (PLS-SEM), a multivariate statistical technique used to analyze lots of response variables and explanatory variables simultaneously. PLS-SEM has achieved a universal highlight as the instrument of scientific analysis in medical field as it can be applied in Mediation and Moderation analysis. ${ }^{14,15)}$ This analysis type is not influenced by multicolinearity and free distribution. It only needs small samples, and can be applied in formative and reflective measurement. PLS can be appied in variety of data types, nominal, categorial, ordinal, and ratio.

PLS employs a Variance Based-SEM approach. PLS is used in a causal-predictive analysis with high complexity, and a weak theoretical foundation. Thus, it is useful to predict a dependent variable involving lots of independent variables, as it is the case in this study. In terms of the response, PLS can correlate a set of independent variables to several dependent variables (response). In terms of predictor, it can manage lots of independent variables, even if the predictor shows a multicolinearity. PLS can be implemented in a regression model, can predict one or more dependency in a set or more independent variables. It can be applied in path model, causal path connecting the predictor and its variable responses. ${ }^{16)}$ The software used to analyze in this study is SmartPLS 3.3.2 (SmartPLS GmbH, Boenningstedt, Germany). This study is the first to use maternal factors (maternal education, maternal age, socioeconomic, unintended pregnancy, birth spacing, milk/dairy during pregnancy, supplement during pregnancy, anemia during pregnancy, nutritional status, weight gain during pregnancy, infectious disease during pregnancy, hyperemesis gravidarum), and child factors (birth weight, duration of pregnancy, exclusive breastfeeding, dose infant formula consumption, severe infection disease) on the stunting in the single model to determine their correlation, using PLSSEM model.

\section{Fit measurement for formative models}

In order to assess the model matching in this study, the outer and inner models were measured. The outer models measurements include face validity, convergent validity (outer weights), discriminant validity (Fornell-Larcker Criterion, cross-loadings), collinearity statistics (variance inflation factor [VIF] inner and outer). The inner model measurement was conducted by assessing the latent variable $R^{2}$, path coefficients, effect measurement of $f^{2}$, predictive relevance (cross-validated redundancy) and model fit (the standardized root mean square residual [SRMR] and normed fit index $[\mathrm{NFI}])^{16)}$

\section{Ethical consideration}

All respondents have been provided with a sufficient explana- tion before the study, and they are willing to sign the agreement letter. This study has obtained approval from the Health Research Ethics Committee, Registration Number: KEPK/UMP/29/IX/ 2019.

\section{Results}

\section{Characteristics of respondent}

The results of the cross-tabulation analysis in Table 1 discovered that mothers with low education, $<20$ years or $>35$ years of age at pregnancy, experienced more stunted child, while mothers with low income did not differ significantly from mothers with

Table 1. Cross-tabulation of maternal characteristics in the stunting versus nonstunting group

\begin{tabular}{|c|c|c|}
\hline Characteristic & $\begin{array}{l}\text { Stunting } \\
(n=132)\end{array}$ & $\begin{array}{l}\text { Nonstunting } \\
\quad(n=132)\end{array}$ \\
\hline \multicolumn{3}{|l|}{ Maternal education } \\
\hline Not junior high school graduate & $74(56.1)$ & $44(33.3)$ \\
\hline Junior high school graduate & $58(43.9)$ & $88(66.7)$ \\
\hline \multicolumn{3}{|l|}{ Maternal age (yr) } \\
\hline 20-35 & $88(66.7)$ & $106(80.3)$ \\
\hline$<20$ or $>35$ & $44(33.3)$ & $26(19.7)$ \\
\hline \multicolumn{3}{|l|}{ Socioeconomic } \\
\hline Middle-high income & $4(3)$ & $10(7.6)$ \\
\hline Low income & $128(97)$ & $122(92.4)$ \\
\hline \multicolumn{3}{|l|}{ Unintended pregnancy } \\
\hline Intended pregnancy & $56(42.4)$ & $84(63.6)$ \\
\hline Unintended pregnancy & $76(57.6)$ & $48(36.4)$ \\
\hline \multicolumn{3}{|c|}{ Birth spacing (interval between birth and subsequent births) (yr) } \\
\hline $2-5$ & $54(40.9)$ & $88(66.7)$ \\
\hline$<2$ yr or $>5 y r$ & $78(59.1)$ & $44(33.3)$ \\
\hline \multicolumn{3}{|l|}{ Milk/dairy during pregnancy } \\
\hline Routine & $30(22.7)$ & $78(59.1)$ \\
\hline Never or rarely & $102(77.3)$ & $54(40.9)$ \\
\hline \multicolumn{3}{|l|}{ Supplement during pregnancy } \\
\hline Routine & $50(37.9)$ & $92(69.7)$ \\
\hline Never or rarely & $82(62.1)$ & $40(30.3)$ \\
\hline \multicolumn{3}{|l|}{ Anemia during pregnancy } \\
\hline Yes & $84(63.6)$ & $56(42.4)$ \\
\hline No & $48(36.4)$ & $76(57.6)$ \\
\hline \multicolumn{3}{|l|}{ Nutritional status } \\
\hline$\geq 23.5 \mathrm{~cm}$ arm circumference & $30(22.7)$ & $76(57.6)$ \\
\hline$<23.5 \mathrm{~cm}$ arm circumference & $102(77.3)$ & $56(42.4)$ \\
\hline \multicolumn{3}{|c|}{ Weight gain during pregnancy (total gestational weight gain) (kg) } \\
\hline $7-12$ & $72(54.5)$ & $102(77.3)$ \\
\hline$<7$ & $60(45.5)$ & $30(22.7)$ \\
\hline \multicolumn{3}{|l|}{ Infectious disease during pregnancy } \\
\hline No infection disease or mild infection & $38(28.8)$ & $78(59.1)$ \\
\hline Severe infection disease & $94(71.2)$ & $54(40.9)$ \\
\hline \multicolumn{3}{|l|}{ Hyperemesis gravidarum } \\
\hline Yes & $82(62.1)$ & $58(43.9)$ \\
\hline No & $50(37.9)$ & $74(56.1)$ \\
\hline
\end{tabular}

Valuesa are presented as number (\%). 
middle income for having stunted child. Mothers with unintended pregnancy had more stunted child than mothers with intended pregnancy. The interval between birth and subsequent births (IBBSB) $<2$ years had more tendency to have stunted child than those with longer interval, $>2$ years. Mothers who rarely consume milk, vitamins, and folic acid during pregnancy have more opportunity to have stunted child than they regularly did. Preg. nant women with anemia and upper arm circumference $<23.5$ $\mathrm{cm}$ are also more likely to get stunted child. During pregnancy, mothers often experience severe infections, and mothers with hyperemesis gravidarum were more likely to have stunted child.

A child with low birth weight $(<2.5 \mathrm{~kg}$ ) and born prematurely are more likely to be stunted. Besides, one not-exclusively breastfed also tended to be more stunted than another exclusively breastfed. A child consuming milk formula $>400 \mathrm{~g} / \mathrm{wk}$ at the age of more than 6 months was less likely to experience stunting. A child who often experienced severe infectious diseases at the age $<2$ years had a higher chance to be stunted than the one with milder infections (Table 2).

Table 2. Cross-tabulation of child characteristics in the stunting versus nonstunting group

\begin{tabular}{|c|c|c|}
\hline Characteristic & $\begin{array}{l}\text { Stunting } \\
(\mathrm{n}=132)\end{array}$ & $\begin{array}{l}\text { Nonstunting } \\
\quad(n=132)\end{array}$ \\
\hline \multicolumn{3}{|l|}{ Sex } \\
\hline Male & $74(56.1)$ & $66(50)$ \\
\hline Female & $58(43.9)$ & $66(50)$ \\
\hline \multicolumn{3}{|l|}{ Age (yr) } \\
\hline Male & $3.08(2-4.9)$ & $3.06(2-4.8)$ \\
\hline Female & $2.92(2.2-4.2)$ & $2.96(2-4.8)$ \\
\hline \multicolumn{3}{|l|}{ Length/high (cm) } \\
\hline Male & $85.4(78-99)$ & $95.8(82-108)$ \\
\hline Female & $83.4(74-93)$ & $93.4(83-108)$ \\
\hline \multicolumn{3}{|l|}{ z score } \\
\hline$>2 \mathrm{SD}$ (tall) & $0(0)$ & $0(0)$ \\
\hline$-2 \mathrm{SD}$ to $2 \mathrm{SD}$ (normal) & $0(0)$ & $132(100)$ \\
\hline-3 SD to $<-2$ SD (short) & $104(78.8)$ & $0(0)$ \\
\hline$<-3$ SD (very short) & $28(21.2)$ & $0(0)$ \\
\hline \multicolumn{3}{|l|}{ Birth weight (kg) } \\
\hline$\geq 2.5 \mathrm{~kg}$ & $66(50.0)$ & $106(80.3)$ \\
\hline$<2.5 \mathrm{~kg}$ & $66(50.0$ & $26(19.7)$ \\
\hline \multicolumn{3}{|c|}{ Duration of pregnancy/premature } \\
\hline Aterm & $76(57.6)$ & $108(81.8)$ \\
\hline Preterm/premature & $56(42.4)$ & $24(18.2)$ \\
\hline \multicolumn{3}{|l|}{ Exclusive breastfeeding } \\
\hline Yes & $28(21.2)$ & $88(66.7)$ \\
\hline No & $104(78.8)$ & $44(33.3)$ \\
\hline \multicolumn{3}{|c|}{ Dose infant formula consumption/wek } \\
\hline$\geq 400 \mathrm{~g}$ & $18(13.6)$ & $84(63.6)$ \\
\hline$<400 \mathrm{~g}$ & $114(86.4)$ & $48(36.4)$ \\
\hline \multicolumn{3}{|l|}{ Severe infection disease } \\
\hline Yes & $98(74.2)$ & $34(25.8)$ \\
\hline No & $34(25.8)$ & $98(74.2)$ \\
\hline
\end{tabular}

Valuesa are presented as mean (range) or number (\%).

SD, standard deviation.

\section{Model fit evaluation}

For the measurement of the outer model, face validity assessment was conducted by observing the correlation between indicators and latent variables in the previous studies, which proved significant and robust. Several indicators in this study had outer weight values $<0.20$ and were not significant $(P>0.05)$. Nevertheless, these indicators were maintained. Fornell-Larcker Criterion of the latent variable in this study was $>0.50$. The value of cross-loadings indicated that each indicator obtained lower correlation value with other latent variables than the latent variable itself. The collinearity statistics test results demonstrated the VIF value of $<5$, which meant that there was no multicollinearity.

The inner models measurement obtained $R^{2}$ of 0.515 which meant that the exogenous variable was able to explain endogenous variables in the moderate category. Path coefficients presented a positive and significant value $(t>1.96 ; P<0.05)$. The value of $f^{2}$ was 0.345 , meaning that exogenous latent variables showed a substantial influence on the structural level. The value of $Q^{2}$ was $0.429(>0)$, meaning that the observation value was excellent. The results of the SRMR analysis indicated a value of $0.048(\mathrm{SRMR}<0.08)$ and the NFI value of 0.911 (NFI>0.90), which meant that the model obtained a good fit and the fit model was $91.1 \%$. From the inner and outer measurement results, it can be drawn that the model can explain the correlation between exogenous and endogenous constructs.

\section{Hypotesis test}

To determine the influence path of maternal factors and child factors to the stunting incidcence and to ensure the significant indicators which constitute maternal and child factors, this study employed PLS Bootstrap method with 5,000 resamplings to reach an inferential statistics. The analysis results demonstrated a significant effect of maternal factors on the occurrence of stunting (path coefficient $=0.303, t=3.527, P<0.001$ ). The effect of maternal factors on the incidence of stunting was $30.3 \%$. Indicators which contributed a significant effect on maternal factors on stunting were birth spacing, nutritional status, weight gain during pregnancy, and infectious disease during pregnancy (outer weights $>0.20, t>1.96, P<0.05$ ), while the indicators of maternal education, maternal age, socioeconomic, unintended pregnancy, milk/dairy intake during pregnancy, supplement during pregnancy, anemia during pregnancy, and hyperemesis gravidarum did not contribute a significant effect (outer weights $<$ $0.20, t<1.96, P>0.05)$. The maternal factor indirectly had a substantial impact on stunting through child factors (path coefficient $=0.282, t=4.762, P<0.001$ ), with an effect of $28.2 \%$.

The analysis results indicated that there was an effect of child factors on the occurrence of stunting (path coefficient $=0.498$, $t=5.749, P<0.001)$. The influence of the child factor on the occurrence of stunting was 49.8\%. All indicators (birth weight, duration of pregnancy, exclusive breastfeeding, dose infant formula consumption, and severe infection disease) contributed a significant effect on child factors so that it affected the occurrence of stunting, namely (outer weights $>0.20, t>1.96, P<0.05$ ). 
Maternal factors also significantly influenced child factors (path coefficient $=0.567, t=10.014, P<0.001$ ) by $56.7 \%$. This meant that all the mother factors would affect child factors, i.e., low birth weight, premature, insufficient exclusive breastfeeding and formula milk, and children with infectious diseases. They include low education, age of pregnancy (either too young or too old), low socioeconomic conditions, unintended pregnancies, too close spacing, no milk and supplements intake, anemia during pregnancy, inadequate nutritional status, low weight gain, infection during pregnancy, and hyperemesis gravidarum.

The moderation analysis results demonstrated that maternal and child factors were moderating predictor variables of stunting occurrence $(t=0.580, P>0.05)$. This means that stunting could be predicted through child factors and maternal factors through their indicators. The path model of the effect of maternal and child factors on the occurrence of stunting can be seen in Fig. 1.

\section{Discussion}

\section{Maternal factors to stunting (direct and indirect effect)}

Mother's knowledge about nutrition and child health may affect the nutritional status and health of children. Maternal nutritional knowledge such as selection and feeding, exclusive breastfeeding, and formula feeding according to the dosage after 6 months will produce good nutrition for their children. ${ }^{4)}$ Maternal knowledge about child health in previous studies also significantly reduced infant mortality and stunting. ${ }^{17)}$ However, this study's educational indicator was not significant in determining the maternal factors that cause stunting.

There was a significant correlation between maternal age and the occurrence of stunting in previous studies. Children of adolescent mothers were 8 times more likely to be stunted than mature mothers. ${ }^{5)}$ However, in this study, maternal age indicators were not significant in forming maternal factors that impacted on stunting. Maternal age may not have a direct impact on the occurrence of stunting but through other factors. Some of the factors such as adolescent mothers which less able to ensure adequate nutritional intake for their children since the mother is still in the growing stage and pregnant adolescent mothers will compete for nutrition with the development of the fetus so that the fetus is more at risk of to be born with less weight compared to adult mothers. Adolescent mothers may also be psychologically unprepared to breastfeed the baby after delivery. Teenage mothers may experience personal stress from having a premature pregnancy and dropping out of school. Those problems are likely to affect their children's growth and development, resulting in malnutrition and other growth impediments. ${ }^{18)}$

Families with low socioeconomic levels (poor families) are at a much higher risk of having stunted child than high socioeconomic families. $\left.{ }^{6}\right)$ However, based on the study, family socioeconomics was not significant in determining maternal factors that cause stunting in children. Yet, socioeconomic indicators may have an indirect effect on the occurrence of stunting through other indicators that shape maternal and child factors, such as nutritional status, anemia during pregnancy, birth weight, and

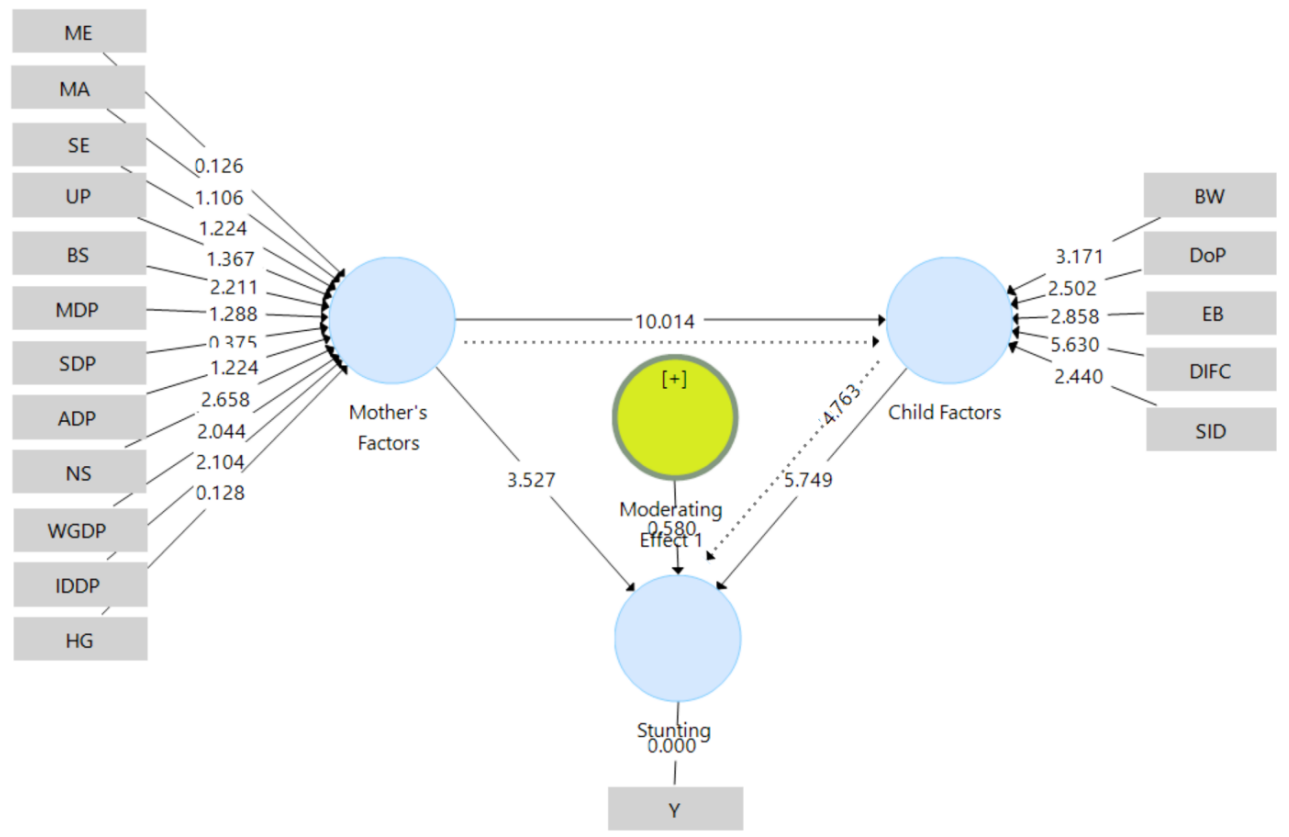

Fig. 1. Path model of the influence of maternal and child factors on the incidence of stunting. ADP, anemia during pregnancy; BS, birth spacing; BW, birth weight; DIFC, dose infant formula consumption; DoP, duration of pregnancy; EB, exclusive breastfeeding; $H G$, hyperemesis gravidarum; IDDP, infectious disease during pregnancy; MA, maternal age; MDP, milk/dairy during pregnancy; ME, maternal education; NS, nutritional status; SDP, supplement during pregnancy; SE, socioeconomic; SID, severe infection disease; UP, unintended pregnancy; WGDP, weight gain during pregnancy; Stunting occurrence $(Y)$. Moderating effect variable of maternal factor plus $(+)$ child factor. Considered significant if $t>1.96 ; P<0.05$. Straight arrows indicate direct effect. Dotted arrows indicate indirect effect. 
the dose of infant formula consumption. Families with low socioeconomic status are more likely to have deprived nutritional status and experience anemia during pregnancy. ${ }^{19)}$ Mothers with poor nutritional status during pregnancy will have babies with low birth weight. ${ }^{20)}$ In addition, families with low socioeconomic levels are more likely not to pay attention to adequate nutrition and milk consumption for their children which hamper children's growth.

Unintended pregnancy indicators did not significantly construct maternal factors that cause stunting in children. However, it may contribute to an indirect effect through child factors, such as in the provision of nutrition and exclusive breastfeeding. Previous studies found that $24 \%-40 \%$ of children from unintended pregnancies were stunted. ${ }^{21,22)}$ This may be caused by the fact that unintended pregnancies are more likely to be neglected either consciously or unconsciously. For instance, by improper feeding, poor mother-child bonding, and poor health care can substantially affect the child's nutritional status.

The interval between the births affects the occurrence of stunting. The interval between the births of children for more than 3 years will not cause the child to be malnutrition, which leads to stunting. The results indicated that the chance of stunting was significantly higher in children born to mothers with 2-3 births $<3$ years IBBSB $(41.1 \%-46.8 \%, P<0.01)$. Mothers with $>3$ births $<3$ years IBBSB have $53.1 \%$ chance of having stunted child $(P<0.01){ }^{23)}$

In this study, the milk/dairy indicator during pregnancy was not significant in forming maternal factors which cause stunting in children. However, this indicator may affect stunting indirectly through child factors. In various evidences, previous studies have revealed that mothers who consume milk during pregnancy have profitable fetal growth and have sufficient birth weight than mothers with low milk intake. ${ }^{24)}$

Previous studies discovered that women who did not take additional supplements during pregnancy experienced 1.67 (odds ratio [OR], 1.674; 95\% confidence interval [CI], 1,118$2,087)$ chance of having stunted and underweight children. Nevertheless, the supplement indicator during pregnancy was not significant maternal factors that cause stunting in children. The supplements in this study were the intake of vitamins, iron, and folic acid during pregnancy. This study has proven that consumption of iron-folic acid supplement in the first 6 months of pregnancy significantly reduces the risk of stunting by $14 \%$ compared to women who did not. ${ }^{25}$

The anemia indicator during pregnancy in this research is not significant in forming maternal stunting factors. A study involving 539 pregnant women found that the occurrence rate of anemia was $18.0 \%$, and $2 \%$ of them experienced a severe anemia. There were 10 stillbirths found at delivery, 16 low birth weight babies, and 2 cases of premature birth. However, the statistical analysis found no significant correlation between anemia and low birth weight, premature birth, or stillbirth. ${ }^{26}$

The nutritional status indicators significantly make up the maternal factors which affect the occurrence of stunting. In this study, nutritional status indicators were assessed based on the body mass index (BMI) and midupper arm circumference (MUAC). This study's results support previous studies which found preconception of maternal nutritional status affects the linear growth of the fetus and the risk of stunting during the first 1,000 days. Lower BMI $\left(<17.5 \mathrm{~kg} / \mathrm{m}^{2}\right.$ or $\left.<18.0 \mathrm{~kg} / \mathrm{m}^{2}\right)$ was significantly associated with a 1.3-time increased risk of child stunting. ${ }^{7)}$ Another study also found that maternal malnutrition (measured by MUAC) was significantly associated with the severity of child malnutrition $(P<0.05){ }^{27)}$ Maternal malnutrition, as seen from MUAC indicators (MUAC cutoff $<21$ to 23 $\mathrm{cm}$ ), is at risk of giving birth to a newborn with low birth weight (OR, 1.9; 95\% CI, 1.7-2.1). ${ }^{28)}$

In this study, the weight gain indicator during pregnancy was significant in forming maternal factors in causing stunting. Preg. nant women should pay attention to weight gain during preg. nancy because it will affect the fetus's development. The Institute of Medicine recommends a range of total weight gain for preg. nant women based on BMI $\left(\mathrm{BMI}<18.5 \mathrm{~kg} / \mathrm{m}^{2}=12.5-18 \mathrm{~kg}\right.$ total gestational weight gain [TGWG]; BMI $18.5-24.9 \mathrm{~kg} / \mathrm{m}^{2}=$ 11.5-16 kg TGWG; BMI 25-29.9 kg/m²=7-11.5 kg TGWG; dan $\mathrm{BMI}>30 \mathrm{~kg} / \mathrm{m}^{2}=5-9 \mathrm{~kg}$ TGWG). ${ }^{29)}$ If the mother experiences an abnormal weight gain during pregnancy, it will affect fetal development.

Infectious disease indicators during pregnancy are also significant in shaping maternal factors that cause stunting. The frequency of infection during pregnancy is one of the main determinants of growth in a child's first 2 years. ${ }^{2)}$ Bacterial, viral, and parasite intrauterine infections will affect fetal development, including premature birth and low birth weight. Babies born prematurely due to intrauterine bacterial infection often experience severe morbidity and long-term effects such as chronic lung disease, asthma, cerebral palsy, and neurodevelopmental problems. ${ }^{8)}$

Hyperemesis gravidarum is related to pregnant women's nutritional adequacy, which affects to the nutritional adequacy of the fetus. Hyperemesis gravidarum can be very unsafe for preg. nant women if it is unmanaged properly because it can lead to malnutrition, electrolyte imbalance, and poor fetal development, such as prematurity and low birth weight which can lead to stunting. ${ }^{30)}$ However, this study discovered that the indicators of hyperemesis gravidarum were not significant in forming maternal factors which contributed on the stunting occurrence.

\section{Child factor and stunting incidence}

The low birth weight of newborns in this study was very significant in determining child factors of stunting. This result supports previous studies that stated that babies with low birth weight $(<2,500 \mathrm{~g})$ have the potential to cause stunting. ${ }^{31)}$ Infants with low birth weight are more susceptible to infectious diseases, which increases the risk of stunting. ${ }^{32)}$ In order to increase children's low birth weight, it is necessary to provide high protein milk intake. However, it is sometimes not accomplished due to family socioeconomic limitations; it also increases stunting risk.

Premature indicators in this study significantly contributed 
stunting. Premature children were twice as likely to be stunted than normal born children (relative risk, 2.13; 95\% CI, 1.932.36). ${ }^{10)}$ Likewise babies with low birth weight, babies born prematurely are also more susceptible to infectious diseases (respiratory tract infection, digestive tract, skin infection, and other infections) because their immune systems are not fully developed. ${ }^{33)}$ Premature babies also have problems with the digestive absorption system, so that the given nutrients cannot be fully absorbed by the body. ${ }^{34)}$ The combination of these factors increases the risk of stunting in premature newborns.

Previous studies found a significant correlation between exclusive breastfeeding and the occurrence of stunting $(P<0.01) .{ }^{11)} \mathrm{In}$ this study, the indicator of exclusive breastfeeding also contributed a significant effect on forming child factors that impacted the occurrence of stunting. Children who are nonexclusively breastfed are more likely to develop respiratory and digestive diseases than children with exclusively breastfeeding. Therefore it can affect their growth and development, which results in stunting. ${ }^{35)}$

The dose indicator of infant formula consumption in this study was significant in forming child stunting factors. This indicator has the highest influential value among all. WHO recommends babies to be exclusively breastfed for the first 6 months of life to achieve optimal growth, development, and health. Subsequently, to meet their growing nutritional needs, babies should receive adequate nutritious and safe complementary foods while breastfeeding until the age of 2 years or more. ${ }^{36}$ After 6 months, the baby's nutritional needs increase, and breast milk is no longer effective in fulfilling their dietary needs; therefore, complementary diets should be given after 6 months. However, due to socioeconomic limitations, parents often do not provide adequate nutrition for their babies. We found that many parents only afford porridge, rice, and even only fruit as complementary diets for breastfeeding; this is, of course, inadequate for their need. Therefore, formula milk's role is quite important as a complement in their dietary needs. In this study, we found a higher stunting occurrence in children whose formula consumption was $<400$ $\mathrm{mg} / \mathrm{wk}$ than in children with milk $>400 \mathrm{mg} / \mathrm{wk}$ at 6-24 months.

The indicator of severe infection disease in this study was also significant in forming child factors which affect the occurrence of stunting. The correlation between child nutrition and infection is two-way; frequent illness can interfere with nutritional status, and malnutrition can increase the risk of infection, both of which have an impact on children's growth and development. ${ }^{12)}$ Previous studies have also found that diarrheal disease, respiratory infections, and fever were correlated with stunting in children aged 6 to 59 months living in underprivileged urban and rural areas. $^{37)}$

In conclusion, the nutrition status, in perinatal period and nutrition intake postmaternity become the important factors to prevent stunting. Mothers who give birth with a relatively short interval, inadequate nutritional status during pregnancy, nonstandard weight gain during pregnancy, and experiencing infectious diseases during pregnancy are the indicators which contribute significantly to the formation of maternal factors which cause stunting. Children with low birth weight, premature, nonexclusively breastfed, consumption of formula milk after 6 months does not match the prescribed dose, and frequently experiencing severe infectious diseases are the indicators that contribute significantly to the formation of child factors which cause stunting. The occurrence of stunting is more affected by the children factor than the maternal factor. However, the maternal factor has a significant effect on the child factor, which impacts on stunting.

\section{Footnotes}

Conflicts of interest: No potential conflict of interest relevant to this article was reported.

ORCID:

Agus Santosa ํ http://orcid.org/0000-0002-1535-8406

Essa Novanda Arif $\odot$ https://orcid.org/0000-0001-7833-3209

Dinal Abdul Ghoni $\odot$ https://orcid.org/0000-0003-1364-7025

\section{References}

1. Woldehanna T, Behrman JR, Araya MW. The effect of early childhood stunting on children's cognitive achievements: evidence from young lives Ethiopia. Ethiop J Heal Dev 2017;31:75-84.

2. Prendergast AJ, Humphrey JH. The stunting syndrome in developing countries. Paediatr Int Child Health 2014;34:250-65.

3. Alam MA, Richard SA, Fahim SM, Mahfuz M, Nahar B, Das, S, et al. Im pact of early-onset persistent stunting on cognitive development at 5 years of age: results from a multi-country cohort study. PLoS One 2020;15: $\mathrm{e} 0227839$.

4. Fadare O, Amare M, Mavrotas G, Akerele D, Ogunniyi A. Mother's nutrition-related knowledge and child nutrition outcomes: empirical evidence from Nigeria. PLoS One 2019; 14:e212775.

5. Wemakor A, Garti H, Azongo T, Garti H, Atosona A. Young maternal age is a risk factor for child undernutrition in Tamale Metropolis, Ghana. BMC Res Notes 2018;11:877.

6. Jonah CMP, Sambu WC, May JD. A comparative analysis of socioeconomic inequities in stunting: a case of three middle-income African countries. Arch Public Health 2018;76:77.

7. Young MF, Nguyen PH, Casanova IG, Addo OY, Tran LM, Nguyen S, et al. Role of maternal preconception nutrition on offspring growth and risk of stunting across the first 1000 days in Vietnam: a prospective cohort study. PLoS One 2018;13:e0203201.

8. Adams Waldorf KM, McAdams RM. Influence of infection during preg nancy on fetal development. Reproduction 2013;146:R151-62.

9. Titaley CR, Ariawan I, Hapsari D, Muasyaroh A, Dibley MJ. Determinants of the stunting of children under two years old in Indonesia: a multilevel analysis of the 2013 Indonesia Basic Health Survey. Nutrients 2019;11: 1106.

10. Sania A, Spiegelman D, Rich-Edwards J, Hertzmark E, Mwiru RS, Kisenge $\mathrm{R}$ et al. The contribution of preterm birth and intrauterine growth restriction to childhood undernutrition in Tanzania. Matern Child Nutr 2015; 11:618-30.

11. Mikawati, Lusiana E, Hasriany. The relationship between exclusive breastfeeding (ASI) and mother height with incident rates stunting among child age 2-5 years in Barombong Public Health Center, Gowa, Sulawesi Selatan. KnE Life Sciences 2019;4:558-67.

12. Dewey KG, Mayers DR. Early child growth: how do nutrition and infec- 
tion interact? Matern Child Nutr 2011; 7 Suppl 3:129-42.

13. Wolf EJ, Harrington KM, Clark SL, Miller MW. Sample size requirements for structural equation models: an evaluation of power, bias, and solution propriety. Educ Psychol Meas 2013;76:913-34.

14. Wang MJ, Lin HM, Hung LC, Lo YT. Non-health outcomes affecting selfcare behaviors and medical decision-making preference in patients with type 2 diabetes: a cross-sectional study. BMC Med Inform Decis Mak 2020;20:74.

15. Waddimba AC, Beckman HB, Mahoney TL, Burgess JFJ. The moderating effect of job satisfaction on physicians' motivation to adhere to financially incentivized clinical practice guidelines. Med Care Res Rev 2017;74:14877.

16. Garson GD. Partial least squares: regression \& structural equation models. Asheboro (NC): Statistical Associates Publishing, 2016.

17. Desai S, Alva S. Maternal education and child health: is there a strong causal relationship? Demography 1998;35:71-81.

18. Habimana S, Biracyaza E. Risk factors of stunting among children under 5 years of age in the Eastern and Western provinces of Rwanda: analysis of Rwanda demographic and health survey 2014/2015. Pediatr Heal Med Ther 2019;10:115-30.

19. Mahanta LB, Roy TD, Dutta RG, Devi A. Nutritional status and the impact of socioeconomic factors on pregnant women in Kamrup district of Assam. Ecol Food Nutr 2012;51:463-80.

20. Woldeamanuel GG, Geta TG, Mohammed TP, Shuba MB, Bafa TA. Effect of nutritional status of pregnant women on birth weight of newborns at Butajira Referral Hospital, Butajira, Ethiopia. SAGE Open Med 2019;7: 2050312119827096.

21. Baschieri A, Machiyama K, Floyd S, Dube A, Molesworth A, Chihana $\mathrm{M}$, et al. Unintended childbearing and child growth in Northern Malawi. Matern Child Health J 2017;21:467-74.

22. Upadhyay AK, Srivastava S. Effect of pregnancy intention, postnatal depressive symptoms and social support on early childhood stunting: findings from India. BMC Pregnancy Childbirth 2016;16:107.

23. Rana MJ, Gautam A, GoliS, Uttamacharya, Reja T, Nanda P, et al. Planning of births and maternal, child health, and nutritional outcomes: recent evidence from India. Public Health 2019;169:14-25.

24. Brantsæter AL, Olafsdottir AS, Forsum E, Olsen SF, Thorsdottir I. Does milk and dairy consumption during pregnancy influence fetal growth and infant birthweight? A systematic literature review. Food Nutr Res 2012; 56:10.3402/fnr.v56i0.20050.

25. Nisar YB, Dibley MJ, Aguayo VM. Iron-folic acid supplementation during pregnancy reduces the risk of stunting in children less than 2 years of age: a retrospective cohort study from Nepal. Nutrients 2016;8:67. 26. Stephen G, Mgongo M, Hussein Hashim T, Katanga J, Stray-Pedersen B,
Msuya SE. Anaemia in pregnancy: prevalence, risk factors, and adverse perinatal outcomes in Northern Tanzania. Anemia 2018;2018:1846280.

26. Stephen G, Mgongo M, Hussein Hashim T, Katanga J, Stray-Pedersen B, Msuya SE. Anaemia in pregnancy: prevalence, risk factors, and adverse perinatal outcomes in Northern Tanzania. Anemia 2018;2018:1846280.

27. Bari A, Sultana N, Mehreen S, Sadaqat N, Imran I, Javed R. Patterns of maternal nutritional status based on mid upper arm circumference. Pakistan J Med Sci 2020;36:382-6.

28. Ververs M tesse, Antierens A, Sackl A, Staderini N, Captier V. Which anthropometric indicators identify a pregnant woman as acutely malnourished and predict adverse birth outcomes in the humanitarian context? PLoS Curr 2013;5:ecurrents.dis.54a8b618c1bc031ea140e3f2934599c8.

29. Monte S, Valenti O, Giorgio E, Renda E, Hyseni E, Faraci M, et al. Maternal weight gain during pregnancy and neonatal birth weight: a review of the literature. J Prenat Med 2011;5:27-30.

30. Petry CJ, Ong KK, Beardsall K, Hughes IA, Acerini CL, Dunger DB. Vomiting in pregnancy is associated with a higher risk of low birth weight: a cohort study. BMC Pregnancy Childbirth 2018;18:133.

31. Rahman MS, Mushfiquee M, Masud MS, Howlader T. Association between malnutrition and anemia in under-five children and women of reproductive age: evidence from Bangladesh Demographic and Health Survey 2011. PLoS One 2019;14:e0219170.

32. Hviid A, Melbye M. The impact of birth weight on infectious disease hospitalization in childhood. Am J Epidemiol 2007;165:756-61.

33. Collins A, Weitkamp JH, Wynn JL. Why are preterm newborns at increased risk of infection? Arch Dis Child Fetal Neonatal Ed 2018;103:F391-4.

34. Henderickx JGE, Zwittink RD, van Lingen RA, Knol J, Belzer C. The preterm gut microbiota: an inconspicuous challenge in nutritional neonatal care. Front Cell Infect Microbiol 2019;9:85.

35. Quigley MA, Carson C, Sacker A, Kelly Y. Exclusive breastfeeding duration and infant infection. Eur J Clin Nutr 2016;70:1420-7.

36. World Health Organization. Essential nutrition actions: improving maternal, newborn, infant and young child health and nutrition. Geneva (Switzerland): World Health Organization, 2013.

37. Bardosono S, Sastroamidjojo S, Lukito W. Determinants of child malnutrition during the 1999 economic crisis in selected poor areas of Indonesia. Asia Pac J Clin Nutr 2007;16:512-26.

How to cite this article: Santosa A, Arif EN, Ghoni DA. Effect of maternal and child factors on stunting: partial least squares structural equation modeling. Clin Exp Pediatr 2022;65;90-7. https://doi.org/10.3345/cep.2021.00094 